\title{
The Pros and Cons of Adopting Technology as a Business Pilot: Global Perspective
}

\author{
Afenya Millicent Selase \\ Zhongnan University of Economics and Law, Wuhan, China \\ Aphu Elvis Selase \\ Huazhong University of Science and Technology, Wuhan, China \\ E-mail: elvis.qapito@yahoo.com
}

\begin{abstract}
Technology has revolutionized human society. A complex scientific knowledge that takes various forms is technology. It is also referred to as a set of meticulous knowledge used to create tools process actions and extricate materials to make work easy. Technology includes equipment such as computers, mobile phones, multimedia, software, games and apps, these are simple tools individuals use in their daily lives to make life comfortable and luxurious. Technology comes in various forms of such as mechanical, electrical, industrial or manufacturing and medical technology. Any establishment set as a going concern for profit maximization is a business. Technology has various benefits which helps businesses achieve its ultimate goal, thus, maximize profit. Technological infrastructure's impact on business efficiency and effectiveness is inevitable. There is a correlation between technology and business profit maximization be it positive or negative, because it has various impacts on businesses. The question is, does the type of technology adopted affect the business? The various types of technology indicate it has different purpose, to be efficient it needs to be used effectively. Today's business world has been massively influenced by internet technology adoption. The utilization among business is inescapable since technology is rapidly regenerating global production, work and business methods, trade and consumption patterns of enterprises and consumers therefore, the paper is to evaluate if there is the need to adopt a particular technology that best fit a business industry.
\end{abstract}

Keywords: Adoption, Businesses, Efficiency, Profit, Technology, Utilization.

\section{Introduction}

The present time is the era of information power, especially since internet use has added new dimensions to information creation and delivery. The definition of technology is subjective to individuals understanding of the meaning of technology, it can be interpreted as investment in equipment and production machinery which ultimately can lead firms to grow in sales. The ease of use of technology, usefulness of technology, compatibility and cost effectiveness are few of the factors that encourage the adoption and utilization of technology. However, a positive connection exists amid technology usage and profit maximization. The internet provides a new economic environment in which virtual business can be conducted. Therefore, as more consumers spend excess time on the internet, it is crucial for businesses to use online, interactive communications to affect consumers directly at all stages of the consumer decision funnel and thus to strengthen offline marketing efforts and in the long run enhance growth. Businesses are driven to embrace appropriate technology with the aspiration of improving their internal operations, improving their product via a rapid communication with their clients, and better promoting and distributing their product and services. Affirmations on the relevance of technology are frequently founded on models made available by the technology acceptance; its success is due to the fact that technology has become the heart of economic growth in countries across the globe. Alberto and Fernando (2007) argued that the use of technology can improve business competitiveness with internet providing numerous opportunities for Small Business to compete equally with large corporation. There is universal consensus that facto rs driving technology adoption rely on the nature of technology, indicating that a one-size-fits-all approach is unfitting and the factors intensify acquiring of specific technologies require specific attention. With the advent of global competition, technological advances and demographic changes, the roles of small business in a country's development have become more important.

Currently, small businesses are increasingly adopting and utilizing technology due to the advent of personal computers, tablets and mobile phones. Leaders who are positively familiar with e-commerce deployment promote and support the innovations. The information age has transformed how business operates. Business now requires quick response to change consumer and client demands of companies. Enterprises are equipped with the help of technology to meet this challenge. Technology is a new development that has improves ways and manner of doing things, in commerce, trade, mining, agriculture, manufacturing, and education and government services. It is to be adopted by business as a way of responding to world dynamics. 
Highlighting the influence of internet in recent years, Oladejo and Adereti (2010) observed that the I990s observed the proliferation and massive growth of internet and intranet technologies, which together are creating a universal and costeffective medium for business to communicate and conduct commerce. Mobile internet commerce can improve business efficiency by disposing information to the workforce remotely and by delivering new channels for customer interaction. Considering the trend toward internet adoption in most organizations is not the important issue whether the users accept the internet or not. The challenge is whether the users are satisfied using the newly adopted technology and whether user satisfaction affects technology usage or not. Successful adoption should be evaluated not in terms of 'actual usage' but in terms of 'user satisfaction'. Since it is difficult to directly measure the contribution of an information system to organizational performance, the perceived market performance is used as a perceptual measure of organizational success and growth.

Unfortunately, businesses have been challenged with increasing rates of business failure and such rates are likely to exacerbate due to the recent global economic hardships. Innovative strategies are obviously needed to improve survival and growth. Also, effective deployment of information and communication technologies (ICT) is likely to be a critical part of such strategies. Successful small businesses often face a major challenge when they grow into a new space either moving to a new location or increasing the size of the current one. As they expand, they need technological infrastructure that keeps pace with their growth and development. Can small business be able to compete with large business given the same platform and technological advancement? Small businesses are seen to be imperative in stimulating entrepreneurial development, contributing to the transformation of the traditional sector into a modern one, creation of employment, reducing rural and urban migration and serving as the training ground for managerial skill acquisition (Akande, 20I I).

\section{What is Technology?}

Technology is such a complex and broad body of knowledge that, it is difficult to comprehend all of its types. Everything in this modern world is technology from every little improvement from nothing to something. However, it can be categorized into information technology, mechanical technology, agricultural technology, medical technology, architectural technology, industrial technology and internet technology. Furthermore, these can be narrow down to networks, computers, appliances, sensors, energy, clothing, accessories, robotics, space, trackers and others. Technology is actually developed from artificial intelligence. Anything out of nature is a form of development, therefore technology. The various sectors of a country's economy each use technology. The Service sector uses technology like stationaries, computers. Networks, mobile phones, iPad, projectors, headsets, software, hardware, information systems, intranet and many more. the Manufacturing sectors deals with plants, machinery, robotics, engines and others which are all born out of technology. Most agricultural technology such as tractors, bulldozer, hoe, cutlass, planters, harvesters etc. is used in the Agriculture sector. Medical technology also uses bio-related technology, ultra sound machines and others. Transportation involves movement and it includes cars, airplanes, trains, pipelines, bicycle, moto bikes and others.

\section{Importance of Technology to Business}

Large-scale computerization, perpetuation of the internet, and the worldwide scope of the web has made dissemination of information quick and broad (Poulter, 2003). Technology has important effects on business operations, no matter the size of the business. There are infinite reasons why technology is important in business. The role of technology in business is expanding and will keep growing as the world is a revolution. Business need to secure their operations, employees and bottom line to utilize the new technological innovations. Business cannot undermine the importance of technology in business anymore, they must accept the benefit technology has to offer which are;

Technology saves time and money, since it now conducts most of the tedious tasks that employees used to be expected to perform. This enables employees to focus their time on more important duties hereby cutting down expense, improving productivity and increase efficiency. Time is a major organizational weapon in so far as business is concerned. The effective exploitation and utilization of time has a positive effect on the regular functioning and development of all civil service institutions (Elvis S. Aphu, 2017)

Technology increase capacity of business as it allows business to reach more people in less time. it creates platforms for a wider market. Business can reach clients, potential clients, suppliers and customers at any part of the world through variety of technological communication mediums. It enables businesses to work as a team on a common platform. Business rely on diverse technology for communication such as email, skype, WeChat, instant messaging, business phones, video conferencing, tango, WhatsApp Messenger and others. Communication breakdowns can result to disasters for business and employees. Leung and Antypas (200I) suggested that mobile internet commerce can enhance business efficiency by distributing information to the workforce remotely and by offering new channels for customer interaction. Technology can assist in ensuring that the business is prepared for the difficult communication.

Technology is essential for a business to succeed. Operational day to day activities rely on technology. Investors, clients and prospective clients evaluate the business technological usage to make informed decisions. Every department in the organization depend on technology to run, HR relies on it to train and develop employees, Accounting employees rely on it to 
complete payroll and execute necessary monetary such as file sharing, Human relations need it improve communication, Operations need it reduces stress by allowing business to schedule important deadlines and meetings using the electronic calendar, and it gives employees the flexibility to perform work functions on mobile device.

Technology improves business by providing new resources. Cyber-attacks are growing at an alarming rate. So too are amazing cyber-security defense such as SOPHO'S DEEP LEARNING TECHNOLOGY. In an age where almost all-important business assets are sorted in the cloud or on endpoint, it is imperative that business adopt security technology to protect their assets. Technology is revolving and growing rapidly, new innovations are been invented consistently. Businesses that are not consistence in looking out for new innovations miss out in development.

Technology keeps employees engaged since it allows them to telecommute; it encourages collaborations between coworkers through tools sharing and improves communication. It promotes hard work and reduces idealness since their job is at stalk. Technology can take over their duties. There are no limitations with technology. Employees expect their employers to provide them with the modern technology which will in turn enable them succeed in performance of their job responsibilities.

Technology improves business competitiveness. The role of technology is not new in the business world. It is a great challenge to compete against businesses that fully employ technological advancements when one's own business is lagging in technology. Technology is the order of the day in this century.

\section{Consequences of Adopting Technology}

Technology is irreproachably integrated into day-to-day operations of business. Those in business depend on technology to keep them updated, overcome competition, inspire innovation, manage inventory, track operation and provide speedy internal and external communication venues. However, just as technology adoptions have benefits; it has other sides unfavorable to business. Technology is expensive in the short run but its benefits are wealth while. New technology often requires firms to hire new employees or train existing employees. Having a revolution technology is an ongoing expense. There is initial purchasing cost, continuous maintenance, update and training expenses. Technology is a continuous investment and that makes it very expensive. Moreover, should a system failure occur, loss of revenue can result due to loss of services rendered or production halted, hereby disappointing and losing customers. Matters with regards to Technology need to be handled by skilled expertise.

Technology utilization exposes business to risk of cyber-crime and fraud. Cyber-crime is any criminal activity down over the internet via computers. Hackers use computer network to commit crimes. Technology doesn't only help businesses, criminals also commit crime with actually been there. They steal money from bank accounts, information they get access to be sometimes sold for money. Despite increased security efforts, hackers are mostly a step ahead. Many employees have access to financial and personal data of clients and customers, therefore, the need to monitor employees to protect information and increase client loyalty and confidentiality. Monitoring employees to protect the information can raise employee privacy issues. Also, securing password and access to information and screening of employees prior to issuing access are necessary challenges that add to company's cost and jeopardize employee relationship. The same technology is used to fight those who abuse it. Should it be so?

With technology serving the larger role in the business. Employees have become disconnected from final products and each other. Job task are often delineated, therefore fewer people are part of the final work which leads to workplace boredom. With the use of technology, communication is sometimes misunderstood often making workers look rude. People reading emails, texts or instant messages cannot accurately measure the tone, body language, facial expression with serve as point of reference for effective communication. However, avenues such as video conferencing have eliminated some of these obstacles.

Technology can distract employees at work hereby lowing their work input level. Aside from issues ceasing work production such as system failure, interruptions can include emails and instant messages. On average, it takes eight minutes for a person to return to creative state after distractions. There are other forms of technology vying for employee time are online games, music and video. Taking a scenario, Elvis is conducting a job interview via skype, Obed is into second hour of his interactive webinar and Milly is walking through the office talking on her cell phone. Add all these distractions to the normal noise of ringing phones, constant emails and noisy fax machine and it makes sense that sometimes it's hard to get actual work done. The time saving advantage is super acid with the constant distractions.

\section{Discussion}

This delivers several contributions suggesting that usefulness, ease of use; compatibility and cost effectiveness are significantly related to usage of technology by business. This is an indication that before business decides to use internet services, they must find it to be compatible with their existing infrastructure if not it would find it difficult to adopt the internet similarly, cost effectiveness is also significant. In spite of exponential growth of technology within business, the rate of technology adoption by these businesses have remained relatively low (Mac-Gregor and Vrazalic, 2005) and this makes business generally have limited access to the market and hence obtain low market share which affects market performance.

Also, internet technology has positive impacts on marketing performance. These processes include increase in sales transactions, increase sales volume, increase sales enquiries, and increase number of customers as it helps aligning customer needs 
with sales and marketing activities. In today's era the digital advertisements, especially the internet usage has help reduced the cost of advertising conspicuously, which is an important factor for business considering their financial constraints. Customer relations are improved by allowing customers direct online access to information for which they would previously have had to telephone, or e-mail for. Moreover, organizations can get the information about their potential customers, clients and competitors through google search rating.

\section{Conclusion}

The factors that influence the adoption and utilization of technology by business are usefulness of technology to business and ease of use (compatibility and cost effectiveness). This indicates that, before business can decide to use internet services, they must find it to be compatible with their existing infrastructure, if not, it would find it difficult to use the internet. Also cost effectiveness is a significant factor to internet technology adoption and utilization since most business objective is to minimize cost and maximize profit. Other benefits of technology include increase in sales transaction, increase sales volume, increase sales enquires and increase in volume of loyal consumers. Internet technology enables market research work which helps business align their products and services to consumer wants which in the long run increase consumer loyalty. As internet technology is a global network where digital advertisement is made. Businesses are able to reach a larger market which intends increase their market to wide range of consumers. However, Consumer relations are improved since consumers can have direct access to information through the internet via e-mail or telephone.

Finally, the factors that hinder the adoption of internet technology by businesses are applicable of business, security and trust issues, expertise in adopting internet, high cost involve in installing internet software, high wages of internet software developers and enough knowledge about the internet and its utilization. The security and trust issues are the main hindrance to internet technology adoption and utilization. The internet is a global network which enhances accessibility for that matter hacker can easily break protocol or passwords to access business information. For that fear of hackers and virus corrupting files, businesses will rather not utilize internet technology. Also, business executives lack knowledge and skills needed to use technology and will rather stick to ache ways.

\section{Suggestive Measures}

The purpose of introducing technology is improve performance and be innovative and businesses need to consider the following when making such decision; align technology and strategic goals, perform a current system analysis to evaluate technological usefulness, communicate technology by developing a training program, integrate technology adoption to change management program and implement technology.

Business enterprises have become the beacon of hope for the struggling economies that are looking for answers to sustainable growth and development. It is critical to recognize the impact of business in the growth of the economy, which includes creation of jobs, increase of GDP (Gross Domestic Product), increase of standard of living, alleviating poverty and achieving societal goals. The growth of the nation's economy, the future of innovation and the sustainability of a growing national population rely on businesses. This is because the business serves as economic growth engine and they need access to the same technology as the big players to level the playing field, be flexible, responsive, and be able to anticipate consumer needs. Adoption of technology is needed for business to be profitable so as to enhance operations.

\section{Reference}

Alberto, B. M., \& Fernando, L. L. (2007). A firm-level analysis of determinants of ICT adoption in Spain. Tec novation.

Akande, O. O. (2013). Does Entrepreneurship Programs Influence business performance? An Empirical Investigation of the Nigeria SMEs. International journal of Research in Commerce and Management,4(9).

Aphu E.S (2016). Time Management Within Civil Service Institutions in Ghana. A Case of Accra Metropolitan Assembly.European Journal of Business and Management ,7(30).20I

Oladejo, M. O., \& Adereti, A. S. (2010). The impact of Information Technology on the Performance of Micro finance Institutions in Nigeria. Joumal of Economic Development and Managerial Studies.

Leung and Antypas (200I). Joumal of Business Strategy,200I-Emerald Group Publishing Ltd.

http://www.ro.uow.edu.au.//Mac-Gregor and Vrazalic, (2005)

\section{Copyrights}

Copyright for this article is retained by the author(s), with first publication rights granted to the journal. This is an open-access article distributed under the terms and conditions of the Creative Commons Attribution license (http://creativecommons.org/licenses/by/4.0/) 